\title{
Innovating the Teaching of Chinese Ancient Literature Course by Introducing the Advantages of Regional Cultural Resources --Taking Poems of Mount Zhongnan in Tang Dynasty as an Example
}

\author{
Zhandong Yu
}

(School of Literature, Xi'an University ,710065)

Keywords: Regional Culture; Ancient Literature; Curriculum Reform

\begin{abstract}
Regional cultural resources reflect the precious material and spiritual wealth of an area. They are also cultural resources that students are familiar with and are easy to accept. On the one hand, the introduction of regional cultural resources in the teaching of Chinese ancient literature can enrich and improve the curriculum knowledge system. On the other hand, it can also enrich the humanistic spirit of the curriculum. All of these will inevitably have a positive impact on the spiritual life of college students, and will help them form a sense of honor and belonging to the region they live in, thus establishing confidence in our national culture.
\end{abstract}

\section{Introduction}

As an important human spiritual activity, literature reflects the spiritual outlook of each era and reflects people's ideals of life. Chinese ancient literature, as an extremely important part of the spiritual life history of the Chinese nation, is an extremely important part of Chinese traditional culture. Therefore, in the course of Chinese ancient literature, we not only focus on imparting knowledge, but also hope that students will establish a correct and clear understanding of ancient Chinese culture.

However, due to the large gap between the content of Chinese ancient literature and our society today, students sometimes feel that ancient literature is disjointed from contemporary society and real life when they accept, thus creating a sense of distance in the mind. Therefore, we believe that in teaching we can start from the regional culture that students are familiar with and pay attention to the use of regional cultures with special cultural connotations formed during the development of Chinese literature. These regional cultures are certainly a valuable material and spiritual wealth in an area. They are also cultural resources that are more familiar and easily accepted by students. "Educators and educated people can be immersed in the environment, with an irreplaceable 'local atmosphere' and a close 'affinity' '[1]. , which will inevitably have a positive impact on the spiritual life of young students.

Based on the above reasons and the advantages of being located in Xi'an, we will give special lectures on the Mount Zhongnan poetry of the Tang dynasty when we talk about the Tang poems and their seclusion culture in the Tang dynasty. At the same time, we will organize students to make a trip to the Mount Zhongnan for fieldwork in practical teaching. Students learn about the Tang dynasty's landscape poetry creation and the seclusion culture spirit of the Tang dynasty through a famous mountain.

\section{A Regional Cultural Resource with Strong Local Characteristics -- Mount Zhongnan}

Mount Zhongnan is located in the middle section of the Qinling Mountains in Shaanxi Province. "Chang'an County Records" compiled by someone who lived in Song dynasty written in this way:"Mount Zhongnan is across the south of Guanzhong and is 800 miles away from Qinlong in the west to the Lantian in the east. Some people used to say that outside the Taihang mountains, it is the largest in the area."It is an important geographical symbol for hundreds of miles of China, with its rugged terrain and rugged roads, five large valleys and hundreds of small valleys. Mount Zhongnan has a long history. It has been referred to in "Shang Shu Yu Gong", "The Book of Poetry" and "Shaanhai Jing", also known as the Taiyi mountain, Mount Zhongnan, Zhounan mountain and 
so on, for short, Nan mountain.

In Tang poetry, this landmark mountain adjacent to Chang'an City is a hot spot for men of letters to verse. According to the "All Tang Poetry" and Ji Yougong's "Tang Poetry Chronicle," it was confirmed that there were more than 600 poems about Mount Zhongnan in the Tang dynasty after cross-referencing. These poems cover natural landscapes, Taoism, Buddhism, humanities architecture, roads and transportation, and imperial examination culture. And the creative community contained the most outstanding poets of that era. Some of them became famous for writing Mount Zhongnan, such as $\mathrm{Zu}$ Yong. There are also famous masters of Tang poetry who wrote Mount Zhongnan, such as Wang Wei and Han Yu. Through the writing of Mount Zhongnan, the Tang people raised the level of artistic expression of Chinese landscape poetry to a new height. Through these poems, we can see that the Mount Zhongnan written by the Tang people is a "natural mountain", "reclusive mountain", "religious mountain" and "political mountain".

Natural Mountain. First of all, Mount Zhongnan is a natural mountain. From the aspect of natural geography, Mount Zhongnan is the center of China's mainland, which is recognized as the boundary between South China and North China. It is not only a demarcation between the north and the south in geology, geography, climate, rivers, vegetation, soil and agricultural production, but also a watershed in terms of languages, customs, lifestyles and so on. China and even the world have not yet found a place that can experience such huge differences between two very different natural areas in such a short distance and a short time.

The unification of the Tang dynasty had achieved a vast territory, prosperous economy, and stable politics. In the context of this peaceful era, the scholar-officials embraced the belief of "Climb ten thousand mountains and sail a thousand boats" and made sightseeing a great blessing in life. The vigorous implementation of the imperial examination system, the opening of the Beijing-Hangzhou Grand Canal and the land traffic extending in all directions have also provided literati with the opportunity to frequently travel and visit famous mountains and rivers in the whole country, thus greatly increasing the possibility of close contact between literati and natural landscapes. The spectacular scenery of Mount Zhongnan and the superior location to the capital are just enough to satisfy the Tang dynasty literati's intense curiosity. Therefore, Mount Zhongnan presents a variety of sentiments in the poetry of the Tang dynasty. It is either rugged or extremely powerful, the most representative verse should be Wang Wei's "The towering Tai Yi mountain is near Chang'an City, and the mountain winds along the mountain to the sea." (Wang Wei,"Mount Zhongnan"). "The towering Mount Zhongnan and clear river make people feel relaxed" (Chu Guangxi, "Enjoying the beauty of Mount Zhongnan after Rain"). "The towering Mount Zhongnan makes Chang'an more magnificent. Its shadow can shade millions of households. Mount Zhongnan has its own view, making people have to look up to appreciate its beauty" (Lin Kuan, "Mount Zhongnan"). There are dense forests and green lakes in the Mount Zhongnan. "South of Mount Zhongnan is a very prosperous market, but the greenery of Mount Zhongnan can clear these troubles away." (Pei Shuo, "Mount Zhongnan"). "The Mount Zhongnan can make people feel peaceful and the sky reflected in the water is more beautiful." (Wu Yuanheng, "To Celebrate the Year of Abundance for Nine More Days"); "Looking back at the twilight of the mountains, people can hardly see the scenery of the Mount Zhongnan in the autumn." (Gao Shi, "Enjoying the beauty of Mount Zhongnan after Rain with Xue Si").

Reclusive Mountain. Since ancient times, literati have been indissoluble with seclusion, and the Tang dynasty is also an era with prosperous secluded culture. On the one hand, with the prosperity and development of social politics, economy and culture, the court particularly hopes to promote their noble moral qualities and solve the social moral crisis through favoring hermits. The social ethos of "Value hermits and fight corruption" and the tradition of treating hermits with courtesy are more intense in the Tang dynasty than in previous dynasties. Therefore, the entire Tang dynasty has been filled with seclusion culture. On the other hand, with the deepening of the imperial examination system, the number of people admitted is always small. Every year, a large number of candidates or losers who are about to participate in the imperial examination often live in the mountains to study the books. The Mount Zhongnan is near Chang'an, with little harassment, 
Buddhist temple and clean environment, which makes it an excellent place for a seclusion study. In the Qin and Han dynasties, four famous hermits lived in Shang Shan first and then lived in Mount Zhongnan. In the Han dynasty, Zhang Liang retired from public life and lived in Zibo mountain, the southern foot of Mount Zhongnan. The seclusion tradition of the Mount Zhongnan left by the previous generation provided the Tang people with a secluded cultural atmosphere. Therefore, whether it is a temporary scholar, or the officials who look out over the mountain scenery at Chang'an City, it is inevitable to express the meaning of seclusion in Mount Zhongnan Poetry.

But at this time, the literati's seclusion mentality has changed dramatically compared to the previous dynasties. They long for a lifestyle that softens and compromises the contradiction between official and seclusion. So there was a secluded culture rich in the atmosphere of the Tang dynasty. So this way of entering the government is very popular in the Tang dynasty. In Tang dynasty, people tended to seek for official career for civilians. "The person is in the mountain but the mind is in the court" has become the psychological trend and behavior concept of literati in a whole era. Seclusion has changed from passive evasion to active accession to the world and has even formed a social atmosphere. Many great poets in the Tang dynasty, such as Wang Wei and Li Bai both lived in Mount Zhongnan.

Religious Mountain. As the heyday of Chinese history, the Tang dynasty inherited the excellent cultural heritage of its predecessors on the one hand. On the other hand, it integrated and formed its own unique characteristics, with an all-inclusive attitude. In terms of ideology, it shows the compatibility of Confucianism, Buddhism, and Taoism. Taoism received unprecedented glory in the Tang dynasty. Li Tang dynasty admired Lao Tzu as model. Tang Taizong paid attention to Taoism but restrained Buddhism, and instructed by Lao Tzu's Tao Te Ching, which played a positive role in promoting the Taoism development in Chang'an. Because of the rule's support, the Mount Zhongnan was a Taoist shrine in the Tang dynasty, which embodied the Taoist culture based on the concept of architecture. Moreover, the influence of the Taoist Church of Mount Zhongnan was further expanded in the Tang dynasty. On the one hand, the priests, able men, and Taoist views hidden in Mount Zhongnan deeply drew literati, and they all went to visit the Tao. On the other hand, the natural environment and atmosphere of Mount Zhongnan, which towers into the clouds, and the mysterious and unpredictable nature of the alchemy also stimulated the thirst of the literati to make alchemy.

While Buddhism has a greater influence in Chang'an. Under the influence of Wu Zhetian and Tang Xianzong who extremely worshiped Buddhism, there were more than 160 temples that can be applied for in Chang' an City. The eminent monks and talents are gathered here, and many Buddhist sects are performing here. On the outskirts of Chang'an, there are many famous Buddhist temples in Mount Zhongnan, such as Caotang Temple, Fengde Temple, Qingyuan Temple, Xingjiao Temple, Xiangji Temple, and Huayan Temple. Mount Zhongnan is a Buddhist town second only to the capital, Chang'an. Numerous Buddhist temples and famous monks, the quiet environment and atmosphere suitable for seeking Buddhist culture deeply drew the Tang dynasty literati, which has had a far-reaching impact on their world outlook, outlook on life, ways of thinking, and creative methods. The poetry written by the literati in Mount Zhongnan also in turn raised the popularity of Mount Zhongnan. It is not an exaggeration to say that all famous poets in the Tang dynasty wrote poems about traveling to temples or Taoism in Mount Zhongnan.

Political Mountain. In addition to being a resort for seclusion and recreation, Mount Zhongnan is also a political mountain. In terms of its location, Mount Zhongnan is the gateway to the capital Chang'an and its geographical location is very important. Its steep mountains are indeed a natural barrier to guard the capital, which is easy to defend and difficult to attack. It has been a military place since ancient times. Moreover, Mount Zhongnan is also the geographical, political, cultural, and economical point of contact with Chang'an. Travelling from the capital to Bashu, Hanzhong, and Southeast must pass through Mount Zhongnan. In the mountains, there are Ziwu Valley, Tangluo Valley, Wuguan, Lantian Road and Baoxie Road and so on, which lead to each state's roads. There was no lack of literati on these roads, and even there was a trace of the emperor in the glorious age of the Tang dynasty. Therefore, each road in Nan mountain not only has the importance 
of military affairs, but also has the important significance of political, economic, and cultural communication. It is connected with the Chang'an and not only has a geographically integrated nature. In the eyes of the literati, this mountain, standing in the south of Chang'an City, is the only way for them to look into or walk into the north. It is not only a boundary of the nature, administration and culture between the North and the South, but also a north-south dividing line with the meaning of the nation in the eyes of the literati.

\section{The Combination of Regional Culture and Practice Teaching}

Cultivating students' awareness of inheritance and protection of excellent culture is one of the goals of teaching Chinese ancient literature. Through field trips to deepen students' understanding of the region's culture, which is in itself an inheritance of regional culture. Influenced by the excellent regional culture will certainly enhance students' humanistic qualities while deepening their love of regional culture, and establish a sense of honor and belonging to the region. These students will become participants and witnesses of local cultural construction after graduation.

Therefore, students have accumulated a certain amount of knowledge after explaining the Mount Zhongnan poetry of the Tang dynasty, we will organize students to conduct field trips and special research activities. Because the writing of Zhongnan's poetry involves a wide range, we are generally a group of seven or eight students to determine a topic for field trips and special studies. Through such a research study process, students can develop the ability to collect and organize data and master methods of investigation and interview. And it is very gratifying that students discovered an embarrassing problem through investigation and research. The Mount Zhongnan, which has a high status in the Tang dynasty, is not the focus of tourism in Xi'an today. Today, the route to Xi' an is generally divided into three lines. The focus of the East Line is Huaqing Hot Springs at Lishan Mountain, Mausoleum of Emperor Qin Shihuang, and the Terracotta Warriors and Horses Museum. The west-line tourism focuses on Famen Temple, the Qian Mausoleum of Tang dynasty, Zhaoling and Maoling Tomb of the Han dynasty. Northern Line usually chooses Yaowang Mountain, Huangdi Tomb, Red Tourism and Loess Plateau Landscape. Most of these tourist attractions are related to history and culture and are precious legacy left by history. However, for Mount Zhongnan, the importance of its tourism is no less than that of other places. Mount Zhongnan has beautiful landscapes, legendary reclusive celebrities, and unique religious and cultural advantages. However, this famous mountain with a heavy history has been ignored for a long period of time. It has long attached importance to its natural resources development and neglected the protection and development of its historical and cultural resources. This shows that students have jumped out of the circle of ancient Chinese literature, can find problems and try to solve them, and put theory into action and serve the reality, which is what we most hope to see. We will encourage students who are well-founded and have strong research skills to conduct in-depth investigations and studies to find ways and measures to protect and develop the historical relics of Mount Zhongnan.

Mr. Yuan Xingpei once said, "We should pay attention to tapping new information, raising new issues and finding a new perspective while accurately introducing the basic knowledge of literary history." [2] The introduction of excellent regional cultural resources in the teaching of ancient Chinese literature is an effective extension of the curriculum system, and it is also one of approaches to innovate teaching. On the one hand, it allows students to feel the regional characteristics of ancient literature, but also allows students to feel the presence and influence of ancient literature on their own, eliminating the sense of estrangement between times. On the other hand, the practical study of personal field trips will no longer allow the study of ancient Chinese literature to be limited to written knowledge. It is believed that the confidence in national culture is gradually established in such a teaching process.

\section{Acknowledgements}

Shaanxi Province Social Science Fund Project (2014I47); Shaanxi Province Department of Education Special Research Project (2013JK0266) 


\section{Reference}

[1] Qin Yahong. Reasonable Use of Moral Education Resources in Regional Culture - Centering on the Culture of Mount Wutai [J]. Journal of Xinzhou Normal University, 2006(3): 4-6.

[2] Yuan Xingpei. Ancient Chinese Literature (Volume IV) [M]. Beijing: Higher Education Press, 2005: 486.

[3] Peng L, Fang W. Heterogeneity of Inferring Reputation of Cooperative Behaviors for the Prisoners' Dilemma Game [J]. Physica A: Statistical Mechanics and its Applications, 2015, 433: 367-378. 